\title{
STARLIKENESS OF BESSEL FUNCTIONS AND THEIR DERIVATIVES
}

\author{
ÁrpÁd BARICZ, Murat ÇAĞLAR AND ERHAN DENIZ
}

Abstract. In this paper necessary and sufficient conditions are obtained for the starlikeness of Bessel functions of the first kind and their derivatives of the second and third order by using a result of Shah and Trimble about transcendental entire functions with univalent derivatives and Mittag-Leffler expansions for the derivatives of Bessel functions of the first kind, as well as some results on the zeros of these functions.

Mathematics subject classification (2010): 33C10, 30C45.

Keywords and phrases: Bessel functions of the first kind, close-to-convex functions, starlike functions, transcendental entire functions, zeros of Bessel functions, infinite product, derivatives of Bessel functions.

\section{REFERENCES}

[1] J. A. Antonino AND S. S. MiLleR, Third-order differential inequalities and subordinations in the complex plane, Complex Var. Elliptic Equ. 56, 5 (2011), 439-454.

[2] Á. BARICZ, Geometric properties of generalized Bessel functions of complex order, Mathematica 48, 71 (2006), 13-18.

[3] Á. BARICZ, Geometric properties of generalized Bessel functions, Publ. Math. Debrecen 73, (2008), $155-178$.

[4] Á. BARICZ, Generalized Bessel Functions of the First Kind, Lecture Notes in Mathematics, vol. 1994, Springer-Verlag, Berlin, 2010.

[5] Á. Baricz, E. Deniz And N. YaĞMur, Close-to-convexity of normalized Dini functions, Math. Nachr. doi 10.1002/mana.201500009 (in press).

[6] Á. BARICZ, P. A. KUPÁN AND R. SZÁSZ, The radius of starlikeness of normalized Bessel functions of the first kind, Proc. Amer. Math. Soc. 142, 6 (2014), 2019-2025.

[7] Á. BARICZ AND S. Ponnus Amy, Starlikeness and convexity of generalized Bessel functions, Integr. Transforms Spec. Funct. 21 (2010), 641-653.

[8] Á. BARICZ AND R. SzÁsz, The radius of convexity of normalized Bessel functions of the first kind, Anal. Appl. 12, 5 (2014), 485-509.

[9] Á. BARICZ AND R. SZÁsZ, Close-to-convexity of some special functions and their derivatives, Bull. Malay. Sci. Soc. 39, 1 (2016), 427-437.

[10] R. K. Brown, Univalence of Bessel functions, Proc. Amer. Math. Soc. 11, 2 (1960), 278-283.

[11] R. K. BRown, Univalent solutions of $W^{\prime \prime}+p W=0$, Canad. J. Math. 14 (1962), 69-78.

[12] R. K. BRown, Univalence of normalized solutions of $W^{\prime \prime}(z)+p(z) W(z)=0$, Int. J. Math. Math. Sci. 5 (1982), 459-483.

[13] M. E. H. Ismail AND M. E. Muldoon, Bounds for the small real and purely imaginary zeros of Bessel and related functions, Methods Appl. Anal. 2, 1 (1995), 1-21.

[14] C. G. Kokologiannaki and E. N. Petropoulou, On the zeros of $J_{v}^{\prime \prime \prime}(x)$, Integr. Transforms Spec. Funct. 24, 7 (2013), 540-547.

[15] E. KREYSZIG AND J. TodD, The radius of univalence of Bessel functions, Illinois J. Math. 4, (1960), $143-149$.

[16] B. YA. Levin, Lectures on Entire Functions, Amer. Math. Soc.: Transl. of Math. Monographs, vol. 150, 1996.

[17] L. LORCH AND P. SzEGô, Monotonicity of the zeros of the third derivative of Bessel functions, Methods Appl. Anal. 2, 1 (1995), 103-111. 
[18] A. MCD. MERCER, The zeros of $a z^{2} J_{v}^{\prime \prime}(z)+b z J_{v}^{\prime}(z)+c J_{v}(z)$ as functions of order, Internat. J. Math. Math. Sci. 15, 2 (1992), 319-322.

[19] F. W. J. Olver, D. W. Lozier, R. F. Boisvert and C. W. Clark, eds., NIST Handbook of Mathematical Functions, Cambridge Univ. Press, Cambridge, 2010.

[20] S. M. Shah And S. Y. TRimble, Entire functions with univalent derivatives, J. Math. Anal. Appl. 33, (1971), 220-229.

[21] E. A. SKelton, A new identity for the infinite product of zeros of Bessel functions of the first kind or their derivatives, J. Math. Anal. Appl. 267, (2002), 338-344.

[22] R. SzÁsZ, On starlikeness of Bessel functions of the first kind, In: Proceedings of the 8th Joint Conference on Mathematics and Computer Science, Komárno, Slovakia, 2010, 9 pp.

[23] R. SZÁsZ AND P. A. KUPÁN, About the univalence of the Bessel functions, Stud. Univ. Babeş-Bolyai Math. 54, 1 (2009), 127-132.

[24] G. N. Watson, A Treatise of the Theory of Bessel Functions, Cambridge Univ. Press, Cambridge, 1995.

[25] R. Wong And T. LANG, On the points of inflection of Bessel functions of positive order II, Can. J. Math. 44, 3 (1991), 628-651. 